American J. of Engineering and Applied Sciences 3 (2): 265-269, 2010

ISSN 1941-7020

(C) 2010 Science Publications

\title{
Multivariable Proportional Integral Controllers for Multi-Inputs-Multi-Outputs Desalination System Fed by a Photovoltaic Generator
}

\author{
Abderrahmen Ben Chaabene and Anis Sellami \\ Department of Electrical Engineering, Research unit on Electrical Networks and Machines, \\ National Institute of Applied Sciences and Technologies, Tunis, Tunisia
}

\begin{abstract}
Process control is an essential part of the desalination industry that requires for driving at the optimum operating conditions an increase in the life time of the plant and reduction of the unit product cost. The desalination is a highly complex process, so that the majority of dynamic models are of the form of Multi-Inputs-Multi-Outputs (MIMO) systems. Problem statement: Driving a MIMO system is a complex operation because of the interconnections between the inputs and the influence of each one of them on the system outputs. In this study, we present firstly the MIMO dynamic model that we have developed for a Reverse Osmosis (RO) desalination system coupled to a photovoltaic generator, then we propose a PI controller based on a perfect decoupler. Approach: The purpose of this research was to apply a new control strategy based on a decoupled PI controller. The proposed control algorithm was investigated through computer simulation by using Simulink/Mathlab software. Results: The experimental results and simulations showed the efficiency of the proposed controller based on decoupling the input variables of the desalination system. The system outputs are well stabilized. Conclusion/Recommendations: The implementation of the multivariable PI control laws and the experimental results showed clearly the performances of this control strategy to drive the desalination systems and to correct rapidly the outputs behavior which can be influenced by many disturbed parameters.
\end{abstract}

Key words: MIMO process, desalination, PI controller, photovoltaic

\section{INTRODUCTION}

Due to the high product quality and energy requirements, most of modern industry processes, however, are MIMO process. Driving these processes is a complex problem because of the interactions between the input parameters.

Among most of existing approaches, several industrial plant are modeled as first or second order systems and the relations between inputs and outputs parameters are represented by a transfer model based on a transfer function matrix (Robertson et al., 1996). In process control industry, more than $95 \%$ of the control loops are of PID type, this is mainly attributed to its effectiveness and relatively simple structure, which can be easily understood and implemented in practice.

Consequently and with these two points in mind we have choose a MIMO PI control strategy to drive the desalination system after the develop of the MIMO transfer model.

Many formulas have been derived to tune the PID controllers over the years. Therefore, it is highly desirable to develop effective methods to determine the parameters of PID controllers for MIMO systems.

In this study we will firstly present the transfer model that we have develop to make easy the driving of the process, than we will describe the control action based on decoupled controllers applied to parallel transfer function processes. This method shows sensitivity to disturbance and tuning of inner loops, however the conditions were studied and the sensibility was reduced.

Many system parameters can be controlled in an RO unit: feed temperature, $\mathrm{pH}$, conductivity, pressure, flow rate. The present study discusses two parameters which should be monitored and controlled for proper RO: The conductivity $\left(\mathrm{C}_{\mathrm{s}}\right)$ and inlet product water flow $\left(\mathrm{Q}_{\mathrm{s}}\right)$ and does not include the effect of the temperature over the behavior of the system. At industrial scale which requires Moto pumps, the pressure then the pump speed affects the behavior of the system more significantly than the temperature. Additional parameters was not considered however several literature can be consulted (Abbas, 2005; Mandler,

Corresponding Author: Abderrahmen Ben Chaabene, Research Unit on Electrical Networks and Machines, National Institute of Applied Sciences an Technologies, Tunis, Tunisia Tel: 21698353636 
2000) with respect other models. The manipulated variables are the reject brine valve aperture and the angular pump speed.

\section{MATERIALS AND METHODS}

System description: The desalination system that we present is composed by:

- A Photovoltaic (PV) generator

- A DC/AC converter

- Accumulator batteries

- The RO desalination unit

The system configuration shown in Fig. 1 is composed by three compartments: The photovoltaic generator, the electrical adaptor and the desalination unit.

The PV generator consists of an array of photovoltaic cell modules connected in series-parallel combination to provide the desired DC voltage and current.

The adaptor converts the continuous voltage delivered by the battery to an alternative voltage in order to feed the motor pump group which provides pressurized water to the membrane.

The desalination unit is composed by three RO modules, each one of them is composed by a membrane which is constituted of a thin film composite modified polyamide type able to purify feed water containing up to 3,000 ppm of total dissolved solids. These modules have a nominal capacity $1500 \mathrm{~L} / \mathrm{d}$ at $800 \mathrm{kPa}$.

Desalination system model: Because of the variety of parameters, the present study proposes the introduction of a new model that we have developed in (Chaabene et al., 2009) presents the brackish water desalination small unit as a Multi Input Multi Output (MIMO) system. The output variables or set variables are the product flow $\mathrm{Q}_{\mathrm{s}}$ and the product water salinity $\mathrm{C}_{\mathrm{s}}$ (Fig. 2). These two parameters are fundamentals to control water quality (Riverol and Pilipovik, 2005), while the input variables or manipulated variables are the motor pump angular speed $\Omega_{\mathrm{p}}$ and the reject valve opening $\theta_{\mathrm{vr}}$. The water feed salinity $\mathrm{C}_{\mathrm{e}}$ is considered as a disruptive input. The choice of these parameters is based on the experimental results that we'll present in this study. These results show the dependence of the water quality with these parameters.

In addition to these variables there are others which may need to be monitored or controlled such the feed $\mathrm{pH}$ and temperature, the present study does not address the influence of these additional variables.

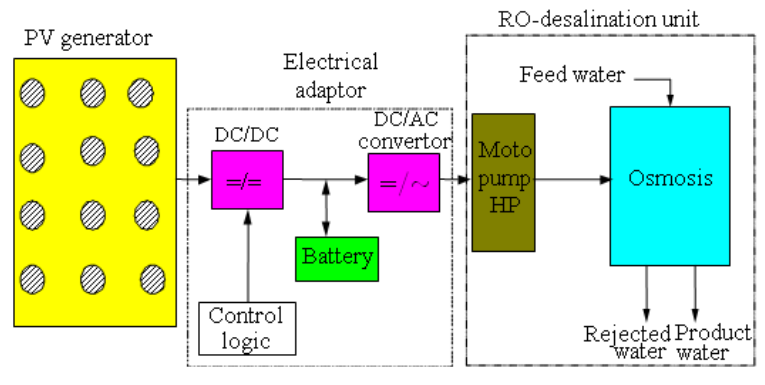

Fig. 1: Desalination system coupled to a photovoltaic generator

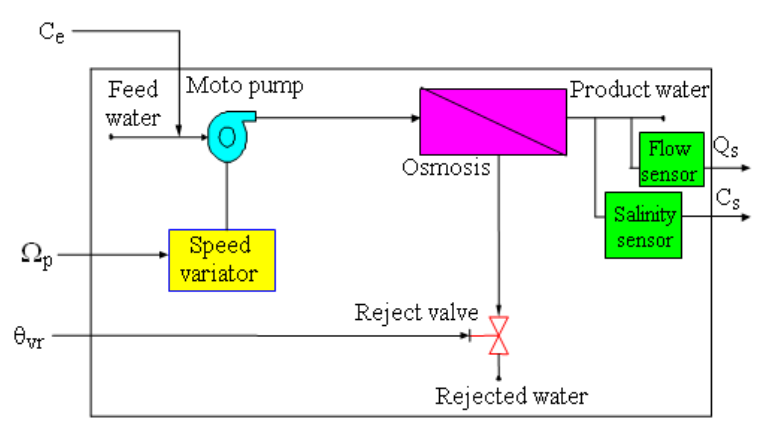

Fig. 2: The desalination unit configuration

The choice of the motor pump angular speed $\Omega_{\mathrm{p}}$ as an input variable is based on the relation between the speed $\Omega$, the water flow $\mathrm{Q}$ and the pump Torque $\mathrm{T}_{\mathrm{e}}$ :

$\mathrm{T}_{\mathrm{e}}=\mathrm{K} \cdot \Omega \cdot \mathrm{Q}$

The pressure applied at the membrane is:

$\mathrm{P}=\mathrm{K} \cdot \Omega^{2}$

where, $\mathrm{k}$ is a constant depending with the pump characteristics and the fluid density.

The unit dynamic model use a transfer function matrix where the relations between output variables and input variables are based on elementary transfer functions noted $G_{i j}$ obeying according to the cases to a second or first order dynamics. This MIMO process with $\mathrm{m}=2$ input variables and $\mathrm{n}=2$ output variables have the following representation:

Where the outputs vector $\mathrm{Y}$ and the control vector $\mathrm{U}$ are given by the following representations:

$\mathrm{Y}=\left[\begin{array}{l}\mathrm{Q}_{\mathrm{s}} \\ \mathrm{C}_{\mathrm{s}}\end{array}\right]$ et $\mathrm{U}=\left[\begin{array}{l}\Omega_{\mathrm{p}} \\ \theta_{\mathrm{vr}}\end{array}\right]$

The transfer matrix $[\mathrm{T}]$ is represented by: 
$\left[\begin{array}{l}\mathrm{Q}_{\mathrm{s}} \\ \mathrm{C}_{\mathrm{s}}\end{array}\right]=\left[\begin{array}{ll}\mathrm{G}_{11} & \mathrm{G}_{12} \\ \mathrm{G}_{21} & \mathrm{G}_{22}\end{array}\right]\left[\begin{array}{l}\Omega_{\mathrm{p}} \\ \theta_{\mathrm{vr}}\end{array}\right]$

Thus the process will be described by the following equation:

$\mathrm{Y}=[\mathrm{T}] \mathrm{U}$

In order to determine the elementary transfer functions, we have realized a serial of experimental measurements using a control and a data acquisition system, then we have used the identification procedure "ident" based on the recursive least square with matlab software (Lee et al., 1998).

The $\mathrm{G}_{\mathrm{ij}}$ expressions are:

$\mathrm{G}_{11}=\left(\frac{\mathrm{Q}_{\mathrm{s}}}{\Omega_{\mathrm{p}}}\right)_{\theta_{\theta_{\mathrm{r}}, \mathrm{C}_{\mathrm{e}}=\mathrm{cte}}}=\frac{\mathrm{k}_{11}}{1+\tau_{11} \mathrm{p}}$

$\mathrm{G}_{12}=\left(\frac{\mathrm{Q}_{\mathrm{s}}}{\theta_{\mathrm{vr}}}\right)_{\Omega_{\mathrm{p}}, \mathrm{C}_{\mathrm{e}}=\mathrm{cle}}=\frac{\mathrm{k}_{12} \omega_{0_{1}}^{2}}{\mathrm{p}^{2}+2 \xi_{1} \omega_{0_{1}} \mathrm{p}+\omega_{0_{1}}^{2}}$

$\mathrm{G}_{21}=\left(\frac{\mathrm{C}_{\mathrm{s}}}{\Omega_{\mathrm{p}}}\right)_{\theta_{\mathrm{r}}, \mathrm{C}_{\mathrm{e}}=\mathrm{cte}}=\frac{\mathrm{k}_{21} \omega_{0_{2}}^{2}}{\mathrm{p}^{2}+2 \xi_{2} \omega_{0_{2}} \mathrm{p}+\omega_{0_{2}}^{2}}$

$\mathrm{G}_{22}=\left(\frac{\mathrm{C}_{\mathrm{s}}}{\theta_{\mathrm{vr}}}\right)_{\Omega_{\mathrm{p}}, \mathrm{C}_{\mathrm{e}}=\mathrm{cte}}=\frac{\mathrm{k}_{22}}{1+\tau_{22} \mathrm{p}}$

The parameters values given by the identification procedure with the disturbed parameter fixed at its least value in practical conditions $\mathrm{C}_{\mathrm{e}}=1.000 \mathrm{ppm}$ are regrouped in the following table:

PI control system design: As in the desalination plant, a manipulated input affects more than one controlled output. One approach to handling this problem is known as decoupling (Riverol and Pilipovik, 2005). The idea is to develop "synthetic" manipulated inputs that affect only one process out each (Gambier et al., 2007). This approach is illustrated at the Fig. 3.

To calculate the PI parameters we have used the Ziegler Nichols modified method which is not detailed in this study (Wang et al., 1998).

The first step is to define the process transfer function matrix:

$\left[\begin{array}{l}\mathrm{Q}_{\mathrm{s}} \\ \mathrm{C}_{\mathrm{s}}\end{array}\right]=\left[\begin{array}{ll}\mathrm{G}_{11} & \mathrm{G}_{12} \\ \mathrm{G}_{21} & \mathrm{G}_{22}\end{array}\right]\left[\begin{array}{l}\Omega_{\mathrm{p}} \\ \theta_{\mathrm{vr}}\end{array}\right]$

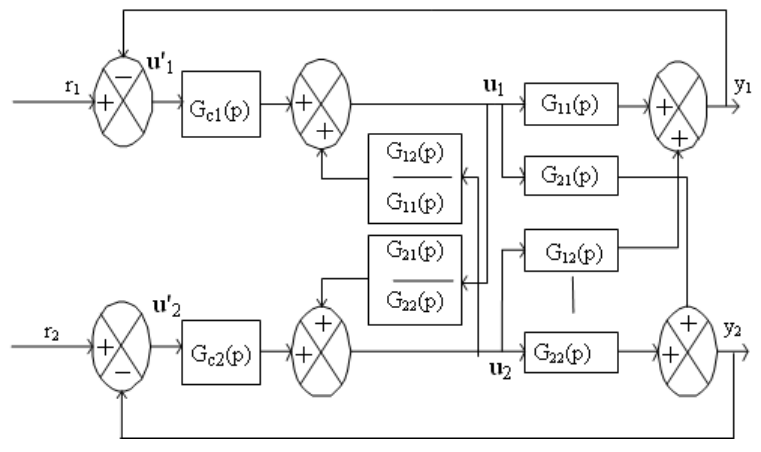

Fig. 3: Control system design

The two outputs $\mathrm{Q}_{\mathrm{s}}$ and $\mathrm{C}_{\mathrm{s}}$ depend with fictive input variables $\Omega_{\mathrm{p}}$ and $\theta^{\prime}{ }_{\mathrm{vr}}$ as:

$\left[\begin{array}{l}\mathrm{Q}_{\mathrm{s}} \\ \mathrm{C}_{\mathrm{s}}\end{array}\right]=\left[\begin{array}{cc}\mathrm{G}_{11} & 0 \\ 0 & \mathrm{G}_{22}\end{array}\right] \cdot\left[\begin{array}{l}\Omega_{\mathrm{p}}^{\prime} \\ \theta_{\mathrm{vr}}^{\prime}\end{array}\right]$

$\mathrm{Q}_{\mathrm{s}}=\mathrm{G}_{11} \cdot \Omega_{\mathrm{p}}^{\prime}=\mathrm{G}_{11} \Omega_{\mathrm{p}}+\mathrm{G}_{12} \theta_{\mathrm{vr}}$

$\mathrm{C}_{\mathrm{s}}=\mathrm{G}_{22} \cdot \theta_{\mathrm{vr}}^{\prime}=\mathrm{G}_{21} \Omega_{\mathrm{p}}+\mathrm{G}_{22} \theta_{\mathrm{vr}}$

$\mathrm{G}_{22} \mathrm{Q}_{\mathrm{s}}=\mathrm{G}_{22} \mathrm{G}_{11} \Omega_{\mathrm{p}}^{\prime}=\mathrm{G}_{22} \mathrm{G}_{11} \Omega_{\mathrm{p}}+\mathrm{G}_{22} \mathrm{G}_{12} \theta_{\mathrm{vr}}$

$\mathrm{G}_{12} \mathrm{C}_{\mathrm{s}}=\mathrm{G}_{12} \mathrm{G}_{22} \cdot \theta_{\mathrm{vr}}^{\prime}=\mathrm{G}_{12} \mathrm{G}_{21} \Omega_{\mathrm{p}}+\mathrm{G}_{12} \mathrm{G}_{22} \theta_{\mathrm{vr}}$

$\mathrm{G}_{21} \mathrm{Q}_{\mathrm{s}}=\mathrm{G}_{21} \mathrm{G}_{11} \Omega_{\mathrm{p}}^{\prime}=\mathrm{G}_{21} \mathrm{G}_{11} \Omega_{\mathrm{p}}+\mathrm{G}_{21} \mathrm{G}_{12} \theta_{\mathrm{vt}}$

$\mathrm{G}_{11} \mathrm{C}_{\mathrm{s}}=\mathrm{G}_{11} \mathrm{G}_{22} \cdot \theta_{\mathrm{vr}}^{\prime}=\mathrm{G}_{11} \mathrm{G}_{21} \Omega_{\mathrm{p}}+\mathrm{G}_{11} \mathrm{G}_{22} \theta_{\mathrm{vr}}$

$\left[\begin{array}{l}\Omega_{\mathrm{p}} \\ \theta_{\mathrm{vr}}\end{array}\right]=\frac{\left[\begin{array}{cc}\mathrm{G}_{11}(\mathrm{p}) \cdot \mathrm{G}_{22}(\mathrm{p}) & -\mathrm{G}_{12}(\mathrm{p}) \cdot \mathrm{G}_{22}(\mathrm{p}) \\ -\mathrm{G}_{11}(\mathrm{p}) \cdot \mathrm{G}_{21}(\mathrm{p}) & \mathrm{G}_{11}(\mathrm{p}) \cdot \mathrm{G}_{22}(\mathrm{p})\end{array}\right]}{\mathrm{G}_{11}(\mathrm{p}) \cdot \mathrm{G}_{22}(\mathrm{p})-\mathrm{G}_{12}(\mathrm{p}) \cdot \mathrm{G}_{21}(\mathrm{p})} \cdot\left[\begin{array}{l}\Omega_{\mathrm{p}}^{\prime} \\ \theta_{\mathrm{vr}}^{\prime}\end{array}\right]$

Then the Fig. 3 shows the control system design.

\section{RESULTS}

To valid the established models and to present the water quality parameters stabilisations with the new control strategy we have applied step type signals for the input variables then the process models were validated from the "ident." Procedure using matlab software.

We have applied a profile of a step input for the aperture reject brine valve, the motor pump speed was fixed at its nominal value $\Omega_{\mathrm{p}}=30 \mathrm{tr} \mathrm{sec}^{-1}$.

Figure 4 and 5 show the validation of the $\mathrm{C}_{\mathrm{s}}$ and the $\mathrm{Q}_{\mathrm{s}}$ models on a step response of the reject valve opening. 
Am. J. Engg. \& Applied Sci., 3 (2): 265-269, 2010

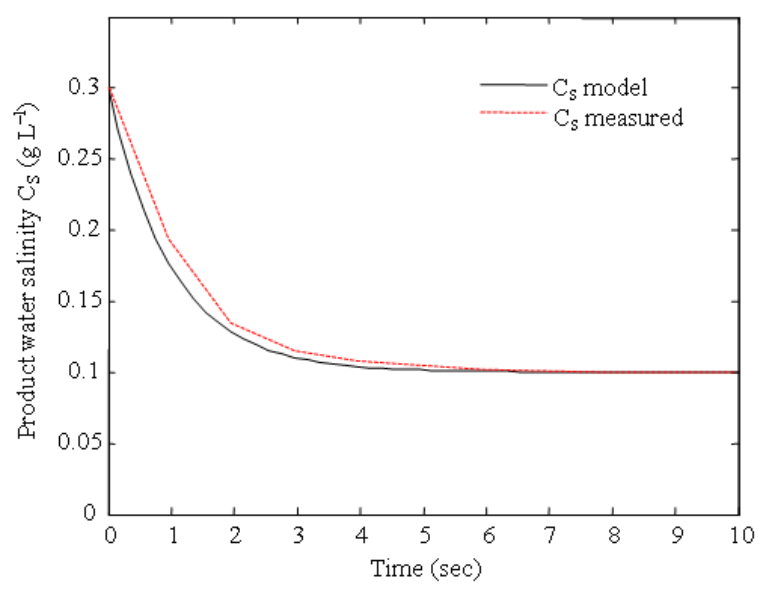

Fig. 4: $\mathrm{C}_{\mathrm{s}}$ model validation on a step response of the reject valve aperture

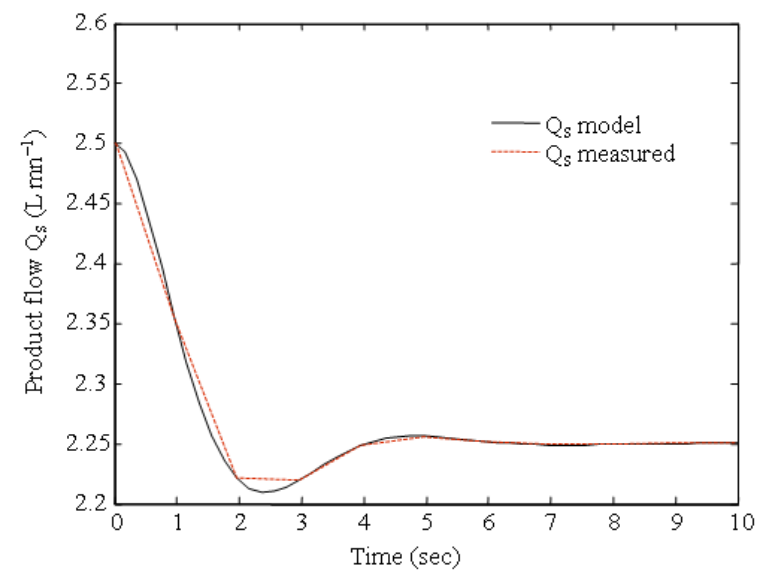

Fig. 5: $\mathrm{Q}_{\mathrm{s}}$ model validation on a step response of the reject valve aperture

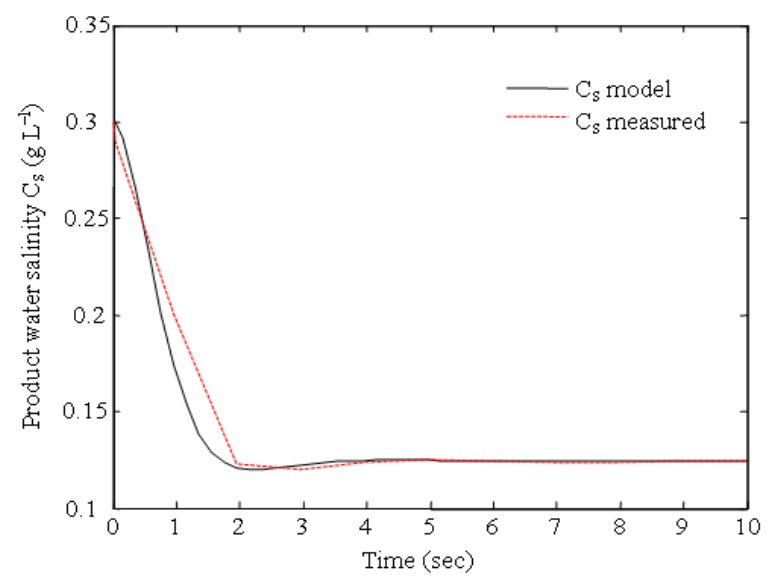

Fig. 6: $\mathrm{C}_{\mathrm{s}}$ model validation on a step response of the motor pump speed

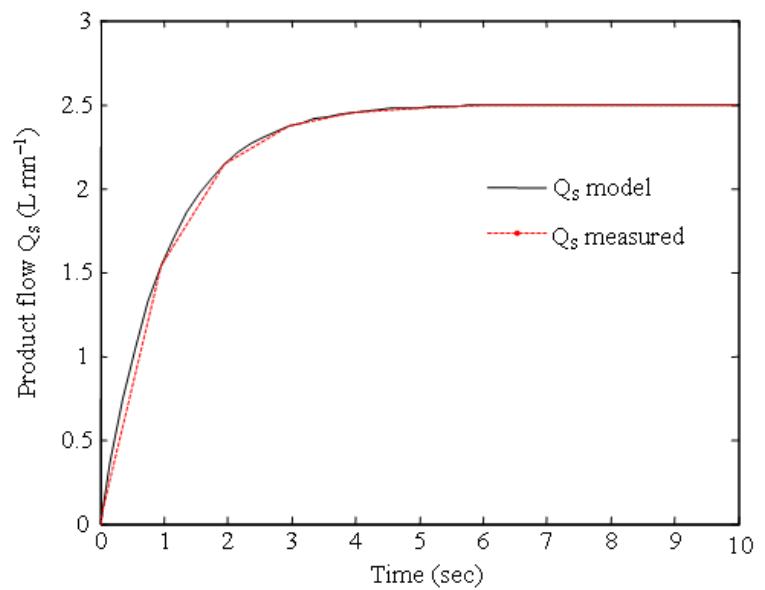

Fig. 7: $\mathrm{Q}_{\mathrm{s}}$ model validation on a step response of the motor pump speed

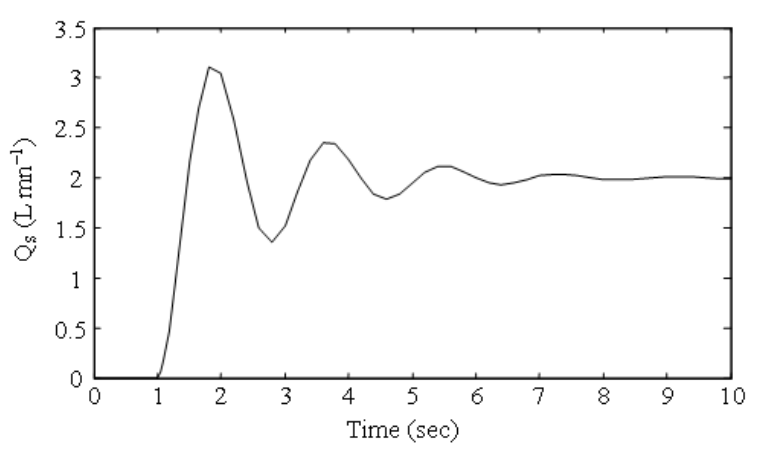

Fig. 8: The behavior of the product water flow $\mathrm{Q}_{\mathrm{s}}$

Figure 6 and 7 valid the Qs and the Cs models when a profile of step input is applied to the motor pump speed $\Omega_{\mathrm{p}}$, the aperture reject brine valve is fixed at the optimum value given by experimental results.

\section{DISCUSSION}

In order to understand the performances of the multivariable PI controller the behavior of the desalination system was shown. Figure 8 and 9 show that the response tried to become stable on an acceptable time with the use of the decoupled PI control.

The decoupling of inputs in order to avoid the influence of theirs fluctuations on water quality parameters shows the ability of this control strategy to compensate errors.

The experimental results and the PI simulation prove the efficiency of the proposed control algorithm. The developed strategy is robust and easy to implement and adapted to the developed system model. 
Am. J. Engg. \& Applied Sci., 3 (2): 265-269, 2010

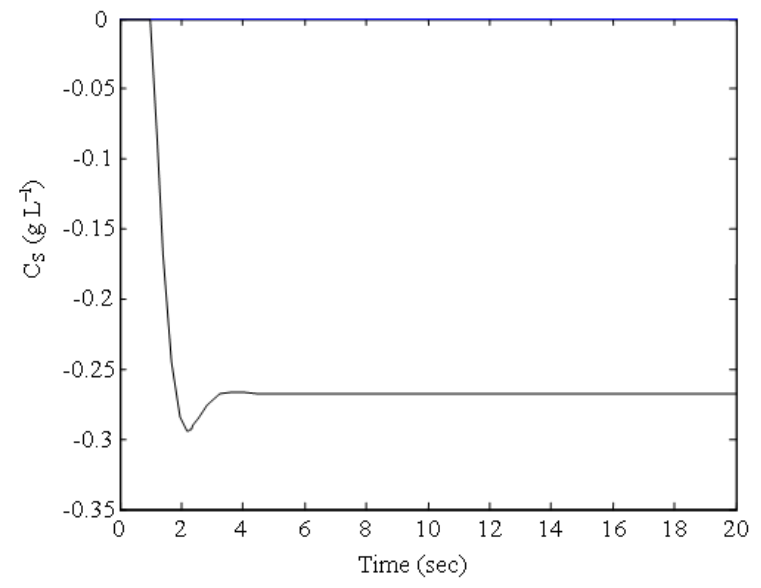

Fig. 9: The behavior of the product water salinity $\mathrm{C}_{\mathrm{s}}$

\section{CONCLUSION}

First, a novel approach of dynamic model depending on manipulated variables of the desalination system has been presented, after that a decoupled PI controller is proposed. The applied PI control strategy has the advantage that it does not need tuning as the classical regulator, it offers an easy solution to the new demand of desalination industry and then it is easier to be implemented.

However the developed model must be refined by the introduction of disturbed inputs and consequently the decoupled controller needs to be modified.

\section{REFERENCES}

Chaabene, A.B., R. Andolsi, A. Sellami and R. Mhiri, 2009. MIMO modeling approach for a small photovoltaic reverse osmosis desalination system. J. Applied Fluid Mechanic, 4: 1-8. http/www.jafmonline.net/modules/htmlarea/myarc hix/filearchive/BFMIMO\%20Modelling\%20Appro ach.pdf
Gambier, A., A. Krasnik and E. Badreddin, 2007. Dynamic modeling of a simple reverse osmosis desalination plant for advanced control purposes. Proceeding of the American Control Conference, July 9-13, IEEE Xplore Press, USA., pp: 4854-4859. DOI: 10.1109/ACC.2007.4283019

Lee, J., W. Cho and T.F. Edgar, 1998. Multiloop PI controller tuning for interacting multivariable processes. J. Comput. Chem. Eng., 22: 1711-1723. DOI: 10.1016/S0098-1354(98)00230-0

Mandler, J.A., 2000. Modeling for control analysis and design in complex industrial separation and liquefaction processes. J. Process Control, 10: 167-175.

http://www.sciencedirect.com/science/journal/0959 1524

Abbas, A., 2005. Model predictive control of reverse osmosis desalination unit. Desalination, 194: 268-280. DOI: 10.1016/j.desal.2005.10.033

Riverol, C. and V. Pilipovik, 2005. Mathematical modeling of perfect decoupled control system and its application: A reverse osmosis desalination industrial-scale unit. J. Automat. Methods Manage. Chem., 2: 50-54. DOI: 10.1155/JAMMC.2005.50

Robertson, M.W., J.C. Watters, P.B. Desphande, J.Z. Assef and I.M. Alatiqui, 1996. Model based control for reverse osmosis desalination processes. Desalination, 104: 50-54. DOI: 10.1016/00119164(96)00026-4

Wang, Q.G., T.H. Lee and Y. Zhang, 1998. Multi loop version of the modified Ziegler- Nichols method for 2 inputs, 2 outputs process. J. Ind. Eng. Chem. Res., 37: 4725-4733. DOI: 10.1021/ie980313r 